\title{
Reference Significance of Foreign Offshore Oil and Gas Cooperation Model Experience to China
}

\author{
Ying Zhang ${ }^{1}$, Jiaofeng Guo ${ }^{2,}{ }^{*}$, and Menghong $\mathrm{Yu}^{3}$ \\ 1. Business School, Suzhou Institute of Technology, Jiangsu University of Science and Technology, \\ Zhangjiagang, 215600, China \\ 2. Development Research Center of the State Council. Beijing,100010, China \\ 3. Jiangsu University of Science and Technology. Zhenjiang, 212100, China
}

\begin{abstract}
For a long time, the oil exploration and development business of Chinese oil enterprises is mostly limited to China, and the international cooperation of transnational oil and gas started late. Therefore, compared with foreign companies, there is still a big gap in understanding the business model of overseas oil and gas industry. Therefore, it is necessary to summarize and learn from the past business model. This paper summarizes the main modes of offshore oil and gas cooperation among global oil companies, compares various modes, and studies the cooperative development mode of offshore oil and gas resources. The research shows that under the lease contract mode, foreign oil companies have greater management rights, but with the continuous development of international oil industry, the government of resource countries has gradually increased its control over foreign oil companies.
\end{abstract}

Keywords: Ocean; Oil and Gas; Cooperation Mode and Experience.

\section{Introduction}

CNOOC's offshore oil field development in China mainly has two stages, one is the preliminary exploration and preliminary development stage before cooperation with foreign companies, and the other is the self support and foreign cooperation stage in the later stage. The first stage laid the foundation for the development of China's offshore oil industry, fully understood the distribution of offshore oil and gas basins, and preliminarily developed some small oil fields. Through the introduction of foreign capital, technology, management and foreign cooperation, China's offshore oil and gas fields have been developed rapidly and efficiently, and the annual output has increased from 170000 tons before cooperation to 18.72 million tons.

With the continuous development of science and technology, many experts have studied foreign marine oil and gas. For example, some domestic teams have studied the foreign offshore oil and gas cooperation model, Maryunina I n. taking Brazil, Norway, the United Kingdom and other countries as examples, they have analyzed the foreign experience of the oil and gas industry import substitution policy as an important part of the national economic industrial development and the effective utilization of natural resources. He emphasizes the important role of the state and its ministries in the formation and Realization of import substitution policies, and concludes that oil and gas clusters affect the development efficiency of national commodity and service production, and obtain and realize the identification characteristics of Brazil and Norway based on internal and external import substitution strategies [1]. China, China and Central Asia one belt, one road initiative, has laid the foundation for further energy cooperation between China and Central Asia, Yu, Xiaozhong and Shuai. have explored the direction and path of energy cooperation between China and Central Asia [2]. Ferrara P determined and explained the design principles of the system jointly developed by Nigeria and sotomi and Principe, and analyzed the follow-up dynamic of system design - the nature of cooperation. The conclusion is that the decision to realize the international development system (JDZ) is beneficial to both countries in many aspects, not just economic aspects [3]. Although the research results of foreign offshore oil and gas cooperation model are quite rich, the experience of offshore oil and gas cooperation model is still insufficient. 
In order to study the experience of offshore oil and gas cooperation model, this paper studies the offshore oil and gas cooperation model, and finds the problems existing in the overseas business model of China's oil and gas enterprises. Therefore, the experience of foreign offshore oil and gas cooperation mode is more mature than that of domestic. Learning from the experience of foreign offshore oil and gas cooperation models is conducive to the development of domestic offshore oil and gas cooperation models.

\section{Method}

\subsection{Main Modes of Offshore Oil and Gas Cooperation of Global Oil Companies}

(1) Prospect of foreign offshore oil and gas cooperation model to China's future offshore oil and gas international cooperation model

The future contract cooperation model will have the following characteristics: first, resource countries will dominate and the contract terms will be more strict. High oil and gas prices and geopolitical instability in major resource countries such as the Middle East will make resource countries, especially those with better resource conditions, have stricter provisions on contract terms such as profit sharing and mining fee tax rate, and limit the exploration depth and recovery period. Second, the contract terms are more adjustable and flexible to attract investors [4]. Third, contracts tend to be standardized, accurate and complex. Fourth, reflect the "balance principle", that is, the degree of resource enrichment, fiscal and tax regulations and the balance of political risks. Generally speaking, the future international oil upstream cooperation will still focus on product sharing contracts, but in terms of business output, it will focus on joint ventures, service contracts and repurchase contracts [5]. Although these three contract models are more stringent than product sharing contracts, they can also create many opportunities for international oil upstream cooperation. When conducting international offshore oil and gas development under the contract cooperation mode, Chinese offshore oil and gas enterprises must deeply study international oil and gas contracts, enhance technical strength, improve equipment level, comprehensively analyze and measure factors such as cost, technology, technology, process and equipment, output and income, as well as political, economic and environmental risks, And choose the cooperation mode according to the specific actual situation.

(2) Main modes of offshore oil and gas cooperation among global oil companies

Offshore oil and gas exploration and development is an industry with high technology, high risk and high investment. There have various modes of international offshore oil and gas development. Countries with marine oil and gas resources in the world have adopted different development models because of their specific national conditions and economic strength. At present, international oil cooperative development generally appears in the form of contracts, which are generally signed by the governments of resource countries and foreign oil companies. At present, international oil contracts widely used in the field of international offshore oil and gas resources development include mining fee tax system contract, product sharing contract, repurchase contract and service contract. At the same time, with the rise of the Democratic liberation movement, many oil producing countries demand economic independence after political independence [6]. Based on the practice of oil and gas cooperation with foreign companies, China has correspondingly adjusted and innovated the commercial terms of product sharing contracts, so that resource countries can increase their share of economic rent when changes in economic environment and resource conditions bring high returns [7]. Clarifying the financing scale and tax mechanism of production sharing contract is also the guarantee factor for the smooth progress of China's oil and gas system reform [8].

(3) Characteristics of leasing system, product sharing contract and risk service contract cooperation mode

Cooperation mode of lease contract: lease contract is the earliest contract form used for oil exploration and development in the world. This form is now widely known as a license agreement. In the early lease contracts, first of all, foreign listed oil companies played a leading role in the 
contracts. Foreign oil companies have actual management rights in the development process and own the oil produced. Resource countries only collect royalties from foreign oil companies. Compared with the early leasing system, the modern leasing system has undergone fundamental changes in nature. Under the modern leasing system, resource countries have full ownership of oil and gas resources, strengthen control over the development of oil and gas resources and strengthen supervision. The benefits available to foreign oil companies are limited by resource countries, and their status is greatly reduced compared with the early leasing system. PSC cooperation mode: PSC is the most widely used cooperation mode in the field of oil and gas cooperation in the world [9]. In PSC, the risk of foreign oil companies is relatively large. If there is no commercial discovery in the exploration stage, they will bear the exploration cost independently, which largely depends on the exploration block area designated by the resource country. If the exploration block is large, the risk is relatively small. Under the mode of product sharing contract, foreign oil companies should pay mining area royalties or resource taxes to resource countries in the development stage. If they make profits, they should also pay income tax. Cooperation mode of risk service contract: compared with the governments of resource countries, risk service contract is a cooperation mode with little risk, but for foreign oil companies, the risk is relatively large, and the service reward is determined, but the risk is great. Therefore, this development model only appears in a few countries and regions in the world. These countries and regions are often areas with low exploration risk or easy to find large oil and gas fields.

(4) Comparison of several main cooperation modes

Each cooperation mode is different in terms of ownership distribution of oil and gas resources, profit sharing, mining area royalties, risk sharing, management rights, management rights, etc. Various cooperative development modes have been adopted in the process of international oil and gas cooperative development. In the process of cooperative development, foreign oil companies and resource countries determine the corresponding cooperative development mode according to their different situations. The relationship between the two parties in the leasing contract mode is a leasing relationship. The legal ownership of oil and gas is transferred at the wellhead, the legal ownership of facilities is owned by the contractor, the franchise belongs to the contractor, the income distribution is self-help mining, the risk sharing is mainly borne by foreign countries, and there are mining area royalties; In the mode of production sharing contract, the relationship between the two parties is a contracting relationship. The legal ownership of oil and gas is transferred at the oil delivery point, the legal ownership of facilities is transferred to the government of the resource country, the management control belongs to the government of the resource country, the income distribution is production sharing, and the risk sharing is mainly borne by foreign countries, with mining area royalties; The relationship between the two parties in the service contract mode is the employment risk service relationship. The legal ownership of oil and gas is not transferred, the legal ownership of facilities is transferred to the government of the resource country, the management control belongs to the government of the resource country, the income distribution is paid by the resource country, the risk is shared by foreign oil companies, and there is no mining area use fee.

\subsection{Overseas Business Model}

(1) Overseas business model theory

Under the dual environment of high risk in countries such as political instability, large economic fluctuation and strong special assets, enterprises should choose a highly controllable business model. The degree of control over overseas business entities should be positively correlated with overseas business experience [10]. When the social and cultural gap is large, the degree of control is low, and the degree of avoidance control is medium and effective. Height control is more effective than medium control. Only when overseas enterprises have sufficient competitive advantages, the highly controlled business model will be more effective. Enterprises have strong business strength and should choose the business model with high degree of control. The content of international oil cooperation is gradually enriched, and the ways of contract are becoming more and more diversified. 
However, the overall purpose of cooperation is always for resource countries to explore, develop and produce their own oil and gas resources in a manner consistent with the interests of both parties. International oil and gas cooperation is usually carried out by resource countries and foreign investors through signing contracts or mutual agreements [11].

(2) Trade model

Trade refers to establishing circulation channels and business relations with target countries through foreign trade. At the same time, it can also increase familiarity with overseas business, accumulate certain experience and prepare for further transnational operation in the future [12]. The prosperity of the international economy will promote the demand for oil and gas resources. However, in the period of international economic stagflation or economic crisis, the decline of consumer demand and capital liquidity will seriously affect the development of oil and gas industry relying on consumption and investment. The international trade environment will also lead to changes in the international economy. In the past two years, the Sino US trade war has delayed the recovery of the international economy. International Economic and trade variables such as the United States liberalizing crude oil export and becoming the first crude oil exporter will be transmitted to the upstream oil and gas industry, which will directly affect the expectation of foreign cooperation of oil resource countries and the investment willingness of investors. In general, long-term crude oil procurement contracts are signed with target countries. This is a traditional international crude oil trade model, which is win-win for both importing and exporting countries.

\subsection{Problems of Overseas Business Model of Chinese Oil and Gas Enterprises}

(1) The overseas business model is relatively single

At present, Chinese oil and gas enterprises can choose up to three business models: trade, investment and contract. Although these models are the traditional overseas oil and gas business models in the world, they are used by almost all countries. Moreover, Chinese petroleum enterprises have gradually gone abroad in accordance with these models in more than ten years of transnational operation. The company has a small scale and low industry concentration. Compared with the international oil and gas exploitation service industry, China has a relatively unique industrial structure. At present, there are many oil and gas exploitation service enterprises in China with scattered layout. The overall scale of oil and gas exploitation service companies is much smaller than that of large international companies, and the industry concentration is low.

(2) Unreasonable trade pattern

There are three main ways of international oil trade: first, sharing oil, which belongs to joint venture and cooperative development, and some resources are directly controlled by development companies; the second is the long-term supply contract. The import price of this kind of oil is low, which requires consumer countries to reach trade agreements with oil producing countries; third, open sales in the international oil market, which is the mainstream of international oil trade. According to the trading mode, it can be divided into spot and futures. Over the years, China's oil industry, especially the upstream oil fields, has been basically monopolized by the three major state-owned oil companies, the entry of foreign-funded enterprises is limited, and it is difficult for private enterprises to enter.

\section{Experience}

\subsection{Object Extraction}

The party with the exploitation right of small oil fields, that is, the party who has the right to decide whether to choose the built small oil fields to cooperate in the development of the built projects, is called the game subject. Other organizations that have the resources and capabilities required by the main parties and have the right to decide whether to participate in the cooperative development of built small oil fields are collectively referred to as game partners; in the game process, the owner has 
two behavior choices, one is to independently develop the built small oil field, the other is to carry out cooperative development.

\subsection{Experimental Analysis}

The cooperative development of oil fields mainly depends on their own independent development ability and the transaction cost of promoting cooperation. When the owner's own independent development ability is high, which can fully meet the needs of effective development of small oil fields, and the transaction cost of promoting cooperation is high, the owner shall choose independent development; on the contrary, enterprises should choose cooperative development. Only after determining many other factors affecting the owner's decision-making, can we analyze it from the perspective of cost and simple game analysis from the perspective of income. If we start from other factors such as risk scale, enterprise anti risk ability, tendency of policies and regulations, cooperation integrity and so on, the input cost and expected income should be fixed.

\section{Discussion}

\subsection{Auxiliary Equipment}

In offshore engineering, the entry threshold of auxiliary equipment market is low, because compared with drilling equipment, auxiliary equipment does not need a difficult technical level, and products do not need too much capital investment. Many of these equipment have a wide range of applications, which can be used not only in the exploration and development of offshore oil and gas, but also in the construction of other offshore projects. As of 2021, the stock and orders (ships and seats) of offshore oil and gas development auxiliary ships are shown in Table 1.

Table 1. Auxiliary ship stock and orders by 2021

\begin{tabular}{|c|c|c|c|}
\hline Equipment type & stock & order & Percentage (\%) \\
\hline Crane ship & 79 & 65 & 82 \\
\hline Laying ship & 56 & 34 & 57 \\
\hline Jack up installation vessel & 45 & 41 & 91 \\
\hline Transport ship & 43 & 23 & 53 \\
\hline
\end{tabular}

It can be seen from the above that crane ship orders account for $82 \%$ of the stock, laying ship orders account for $57 \%$ of the stock, jack up installation ship orders account for $91 \%$ of the stock, and transport ship orders account for $53 \%$ of the stock. The specific presentation results are shown in Figure 1.

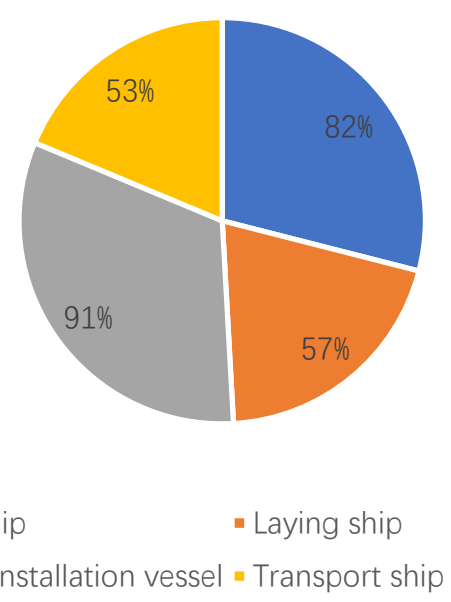

Figure 1. Auxiliary ship stock and orders by 2021 
It can be seen from the sorted data that there are many orders for crane ships, line laying ships and jack up installation ships in the auxiliary equipment, accounting for a large percentage of the stock, which are $82 \%, 57 \%$ and $91 \%$ respectively.

\subsection{Overseas Mergers and Acquisitions}

In offshore engineering, the entry threshold of auxiliary equipment market is low, because compared with drilling equipment, auxiliary equipment does not need a difficult technical level, and products do not need too much capital investment. Many of these equipment have a wide range of applications, which can be used not only for offshore oil and gas exploration and development, but also for the construction of other offshore projects. As of 2021, the inventory and orders (ships and seats) of auxiliary ships for offshore oil and gas development are shown in Table 1.

Table 2. Overseas operation of Sinopec

\begin{tabular}{|c|c|}
\hline management model & amount of money(USD 100 million) \\
\hline Trade & 834.5 \\
\hline International Petroleum Engineering & 543.7 \\
\hline Engineering technical services & 373.5 \\
\hline Overseas mergers and acquisitions & 1784.8 \\
\hline
\end{tabular}

It can be seen from the above that the investment amount of trade business model is US $\$ 83.45$ billion, the investment amount of international petroleum engineering business model is US $\$ 53.47$ billion, the investment amount of engineering technology service business model is US $\$ 373.5$ billion, and the investment amount of overseas M \&amp; a business model is us $\$ 178.48$ billion. The specific results are shown in Figure 2.

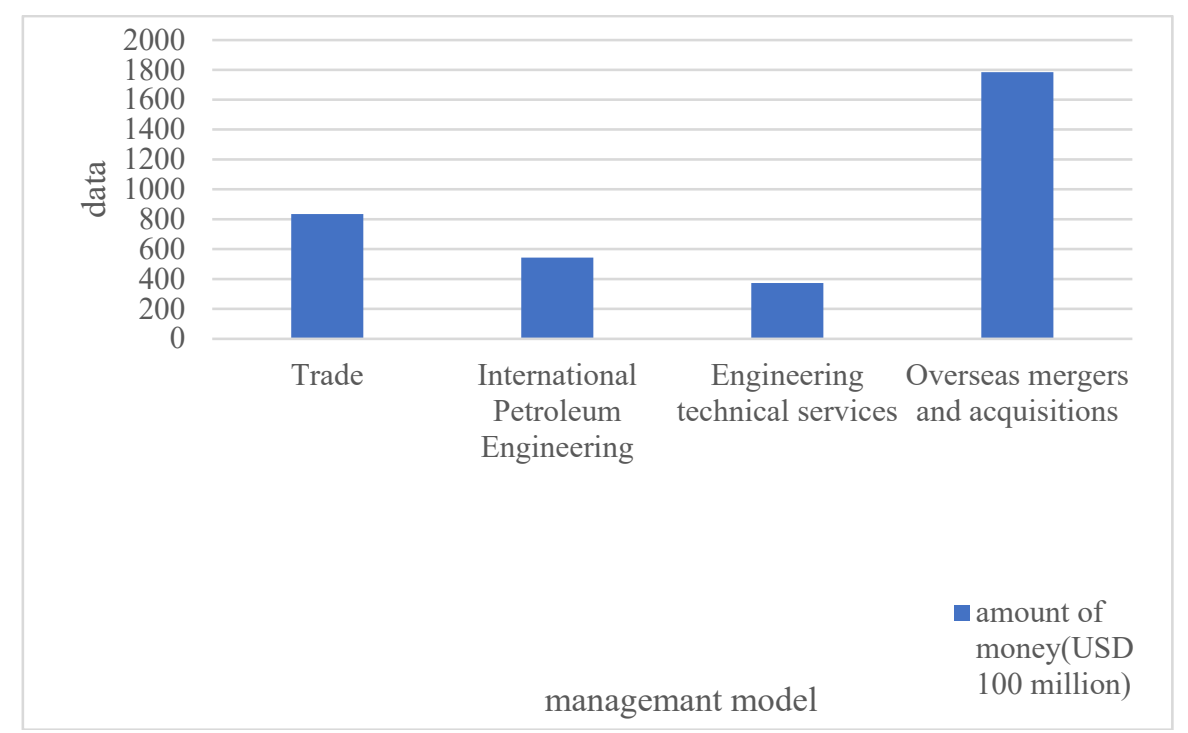

Figure 2. Overseas operation of Sinopec

From the above data, it can be seen that the most important stage for Chinese oil enterprises to obtain oil and gas resources in overseas operation is the trade mode, followed by the contract mode, and finally M \&amp; A. Although the number of mergers and acquisitions is small, Naoto Kan has more mergers and acquisitions than used in the contract model.

\section{Conclusion}

The marine oil and gas laws and policies of modern China are essentially the product of the development of domestic oil and gas industry. The formation of contemporary political power is deeply influenced by the oil policies of successive Chinese governments. Therefore, this paper 
examines the development history of China's modern petroleum experience and the current situation of China's offshore oil and gas industry. This has laid a foundation for the promulgation of China's offshore oil laws and policies. Compared with other countries with marine oil and gas resources, China opened its continental shelf to foreign oil and gas development later. Therefore, China has the opportunity to learn from the experience of other countries and selectively adopt the content of foreign regimes in order to promote its economic development. China's offshore oil laws and policies not only show unique Chinese characteristics, but also integrate the common characteristics of many other offshore oil and gas jurisdictions.

\section{Acknowledgments}

Major Consulting Project of Chinese Academy of Sciences (2019-ZW11-Z-035): Study on the Development Strategy of Comprehensive Oil and Gas Development in the South China Sea; Subject Four: Study on International Cooperation Strategy of Comprehensive Oil and Gas Development in the South China Sea.

\section{References}

[1] Maryunina I N . Experience of Foreign Countries in Import Substitution Policy in Oil and Gas Industry[J]. Vestnik NSUEM, 2019(4):99-113.

[2] $\mathrm{Yu}$, Xiaozhong, Shuai, et al. Discussion on the Innovation of Energy Cooperation Modes between China and Central Asia [J]. China Oil \& Gas, 2019, v.26;No.108(06):15-20.

[3] Ferrara P . Origins of the African Offshore Oil \& Gas Cooperation Milestone: The Nigeria - So Tomé \& Principe Regime[J]. Global Energy Law and Sustainability, 2021, 2(1):51-78.

[4] Elmirzaev, S. THE GREAT FOREIGN EXPERIENCE OF PUBLIC-PRIVATE PARTNESHIPS AND THE PERSPECTIVES IN OUR COUNTRY[J]. International Finance and Accounting, 2019, 2019(3):1414.

[5] Jia Y . EXPERIENCE, PROSPECTS AND PROBLEMS OF COOPERATION BETWEEN CHINA AND TURKMENISTAN IN THE FIELDOF NATURAL GAS[J]. Political Science Issues, 2019(3(33) part: 9): 323-329.

[6] Gulnar D, Madina T, Kuralay B, et al. Innovations in Economic Development in the Modern Conditions of Globalization: Experience of Kazakhstan and Foreign Countries[J]. Revista Gestão Inovação e Tecnologias, 2021, 11(4):3985-3993.

[7] Pin'Koveckaya Y. Alternative Financing of Small and Medium Businesses: Experience of Foreign Countries [J]. Bulletin of Kemerovo State University Series Political Sociological and Economic sciences, 2021, 2021(1):109-122.

[8] Pang W S, Tan J H, Tan H C L, et al. Case series of retained rectal foreign body. A Malaysian experience [J]. Malaysian Family Physician, 2021, 16(2):78-82.

[9] Ushakova N A . Foreign experience in managing physical culture and sports on the example of China[J]. Entrepreneur's Guide, 2021, 14(1):213-222.

[10] J Muzychka, Dadak O. Foreign experience of agricultural insurance and prospects of its adaptation in Ukraine [J]. Scientific Messenger of LNU of Veterinary Medicine and Biotechnologies, 2020, 22 (95): 22-26.

[11] Dyshekova O V, Pilipenko N A, Sarkisyants V R. Communicative nature of the notion term (experience of Russian and foreign linguistics) [J]. Humanities and Social Sciences, 2020, 80(3):73-86.

[12] Tsibikov V A. The foreign experience in training public procurement specialists on the example of the USA, Great Britain and China [J]. Upravlenie, 2020, 7(4):16-23. 